\title{
Stimuli Responsive Surfaces for Fouling-resistant Polymeric Membranes
}

\section{Mondal S*}

Department of Chemical Engineering, The Petroleum Institute, Sas Al Nakhl, Abu Dhabi, PO Box 2533, United Arab Emirates (UAE)

\begin{abstract}
Fouling is a major problem to be addressed with polymeric membrane used in the processes of water treatment. The relation between the physico-chemical properties of the membrane surface and fouling, and approaches to the fouling resistant membrane surfaces by stimuli responsive polymers have been briefly discussed in this article.
\end{abstract}

Keywords: Fouling-resistant; Membrane; Polymer brushes; Responsive polymer; Surface morphology

\section{Introduction}

Polymeric membranes are widely used for the water treatment because of its easy fabrication and low cost. One of the major concerns for membrane based water treatment is fouling which is initially caused by natural concentration polarization during filtration [1]. Fouling reduces the permeate rate over the time and affect the permeate quality as well. The control of membrane fouling is a significant challenge, and considerable efforts are underway both academically and industrially for the development of fouling resistant membranes. Membrane surface modification is an attractive approach to change the surface properties of the membrane in a selective way while preserving macro-structure of the base membrane. Surface treatment with selective stimuli responsive molecules imparts surface functionality to the conventional membranes in order to improve their fouling resistance properties [2]. Hence, development of novel membrane surfaces with improved anti-fouling properties by stimuli responsive polymers has become an interesting research area.

\section{Brief Overview of Membrane Fouling}

One of the major drawbacks for the use of polymeric membrane for water treatment is the membrane fouling. Fouling is the result of undesirable interaction between membrane surface and foulant molecules. Membrane surface morphology viz. surface roughness and charge, surface hydrophilicity/hydrophobicity, and nature of the foulant molecules to be anchor on the membrane surface have remarkable effect on the membrane fouling. Rough membrane surfaces are more likely to prone fouling whereas smother surface reduces possibility for foulants to be attached. Hydrophilic membrane surface tend to reduce the fouling by hydrophobic foulants as the membrane surface attract a layer of tightly bound water molecules (by hydrogen bonding) which would prevent the direct interactions between the foulant and the membrane surface by hydrophobic-hydrophilic repulsion. Negatively charged membrane surface may form fouling through the interactions with positively charged foulant molecules [3-6]. Membrane fouling primarily is due to the adsorption and subsequent cake layer formation by foulant molecules on the membrane surface as well as entrapment of the pores by the foulant molecules (in case of porous membrane). Membrane fouling could be reversible, irreversible or irrecoverable depending on the state of foulants attachment with membrane surface [5]. Reversible foulant adsorption lead to reversible fouling which could be removed by simple hydraulic cleaning. On the other hand, irreversible fouling due to the strong physio-sorption and/or chemisorption of foulants molecules on the membrane surface and in pores. Irreversible fouling requires harsh chemical and/or thermal treatment to remove, which eventually damage the membrane surface as a result of decrease in membrane life. Finally, irrecoverable fouling which is occurs over long periods and cannot be removed by any cleaning [5]. Various physical and chemical techniques have been proposed to modify the membrane surfaces in order to reduce membrane fouling and enhance the membrane performance [1-6]. In this review, author briefly discusses the fouling resistant membrane surfaces by stimuli responsive polymers [1,4-6].

\section{Stimuli-responsive polymers}

Stimuli-responsive polymers (SRP) undergo interesting structural and property changes upon an appropriate external stimulus [7-9]. The external stimuli could be of energetic type viz. light, heat, electric or magnetic field, as well as chemical type viz. $\mathrm{pH}$, organic molecules or biomolecules etc [8]. Responsive properties of polymers in terms of changes in surfaces, shape, transport, electrical, and optical properties on small change of suitable environmental stimuli have been studied by the researchers [7-9]. Responsive polymer brushes could be formed by SRP with one end attached to the substrate surface, which offers alteration of surface property in response to the appropriate external stimulus $[8,9]$. Surface grafting is a promising method to tailor the surface properties of membranes. Grafting density, grafting chain length could be monitored by grafting method employed which will affects the responsive properties of the grafted substrates [10]. Reversible changes to surface physical properties of stimuli-responsive polymers will provide ways of fabricating self-cleaning smart membranes.

\section{Stimuli responsive polymer brushes for fouling-resistant membrane}

Membrane fouling is an inevitable phenomenon however can be minimized and monitor to a certain extent when the mechanisms and responsible substances for fouling are known [5]. Membrane fouling could be control by membrane surface modification with stimuli-responsive polymers. The responsive properties of membrane surface can be adjusted by membrane surface modification with responsive polymers which will response by means of an appropriate external stimulus. The modification by stimuli responsive polymers

${ }^{*}$ Corresponding author: Mondal S, Department of Chemical Engineering, The Petroleum Institute Sas AI Nakhl, Abu Dhabi, PO Box 2533, United Arab Emirates (UAE), Tel: +971 26075150; E-mail: subratamondal@yahoo.com

Received March 10, 2014; Accepted March 17, 2014; Published March 23, 2014

Citation: Mondal S (2014) Stimuli Responsive Surfaces for Fouling-resistant Polymeric Membranes. J Membra Sci Technol 4: e120. doi:10.4172/21559589.1000e120

Copyright: (c) 2014 Mondal S. This is an open-access article distributed under the terms of the Creative Commons Attribution License, which permits unrestricted use, distribution, and reproduction in any medium, provided the original author and source are credited. 
would change the membrane characteristics in terms of the surface morphology, surface chemistry as well as pore structure (in case of porous membrane). Therefore, in addition with the responsive polymer properties, the optimization of polymer brushes in terms of grafting density and grafting chain length are equally important for the surface properties of modified membrane [6]. Surface modifications in a controlled way could accomplish the active sites on both external membrane surface and internal pore surface (in case of porous membrane). Moreover, optimum membrane surface modification may leave the pore size nearly unchanged. Stimuli responsive membrane surfaces change their physical properties in response to the changes in a suitable environmental condition. Changes in the physical properties of the membrane in response to alteration of the desired environmental conditions can be used to minimize fouling and enhance membrane performance [11-14].

\section{Conclusions}

Membrane fouling is one of the major obstacles for the water treatment in the membrane based separation processes. Development of fouling resistant membrane surface (to enhance the membrane performance) requires understanding at a fundamental level, the interactions between the foulants and the membrane surfaces, as well as the type of responsive polymer to be selected to reduce the foulant attachment on the membrane surfaces. This brief discussion provides an insight into the development of smart membranes with enhanced fouling resistant properties by means of surface modification with stimuli responsive polymers. Future advances in fouling control membrane surfaces could be expected from further fundamental research in the molecular level to improve the performance of the membrane processes.

\section{References}

1. Daraei P, Madaeni SS, Ghaemi N, Khadivi MA, Astinchap B, et al. (2013) Fouling resistant mixed matrix polyethersulfone membranes blended with magnetic nanoparticles: Study of magnetic field induced casting. Sep Purif Technol 109: 111-121.
2. Reddy AVR, Trivedi JJ, Devmurari CV, Mohan DJ, Singh P, et al. (2005) Fouling resistant membranes in desalination and water recovery. Desalination 183 301-306.

3. Mondal S, Wickramasinghe SR (2008) Produced water treatment by nanofiltration and reverse osmosis membranes. J Membrane Sci 322: 162-170.

4. Elimelech M1, Phillip WA (2011) The future of seawater desalination: energy, technology, and the environment. Science 333: 712-717.

5. Drews A (2010) Membrane fouling in membrane bioreactors-Characterisation, contradictions, cause and cures. J Membrane Sci 363: 1-28.

6. Shi Q, Su YL, Chen WJ, Peng JM, Nie LY, et al. (2011) Grafting short-chain amino acids onto membrane surfaces to resist protein fouling. J Membrane Sci 366: 398-404.

7. Meng H, Li GQ (2013) A review of stimuli-responsive shape memory polymer composites. Polymer 54: 2199-2221.

8. Zhai L (2013) Stimuli-responsive polymer films. Chem Soc Rev 42: 7148-7160.

9. Meng H, Guoqiang Li GQ (2013) Reversible switching transitions of stimuliresponsive shape changing polymers. J Mater Chem A 1: 7838-7865.

10. Liu F, Urban MW (2010) Recent advances and challenges in designing stimuliresponsive polymers. Prog Polym Sci 35: 3-23.

11. Yang Q, Himstedt HH, Ulbricht M, Qian XH, Wickramasinghe SR (2013) Designing magnetic field responsive nanofiltration membranes. J Membrane Sci 430: 70-78.

12. Yu SC, Chen ZH, Liu JQ, Yao GH, Liu MH, et al. (2012) Intensified cleaning of organic-fouled reverse osmosis membranes by thermo-responsive polymer (TRP). J Membrane Sci 392: 181-191.

13. Himstedt HH, Marshall KM, Wickramasinghe SR (2011) pH-responsive nanofiltration membranes by surface modification. J Membrane Sci 366: 373 381.

14. Mondal S, Wickramasinghe SR, (2012) Photo-induced graft polymerization of Nisopropyl acrylamide on thin film composite membrane: Produced water treatment and antifouling properties. Sep Purif Technol 90: 231-238. 